\title{
Retrospective study of dog bite cases at Ahmadu Bello University, Zaria, Nigeria and its environment
}

\author{
Ajoke Modupeoluwa Ehimiyein ${ }^{1}$, Felix $\mathrm{Nanfa}^{1}$, Ikhide Oluwatoni Ehimiyein ${ }^{2}$ and Balarabe Magaji Jahun ${ }^{3}$
}

1. Department of Veterinary Medicine, Ahmadu Bello University, Zaria, Nigeria; 2. Gimaf Veterinary Consult, Kaduna, Nigeria; 3. Veterinary Teaching Hospital, Ahmadu Bello University, Zaria, Nigeria.

Corresponding author: Ajoke Modupeoluwa Ehimiyein, email: ajokeeo@gmail.com, FN: felixnanfa@yahoo.com, IOE: ehimiyeinikhide121@gmail.com, BMJ : bmjahun@yahoo.com

Received: 06-04-2014, Revised: 08-07-2014, Accepted: 14-07-2014, Published online: 25-08-2014

doi: 10.14202/vetworld.2014.617-621. How to cite this article: Ehimiyein AM, Nanfa F, Ehimiyein IO, Jahun BM (2014) Retrospective study of dog bite cases at Ahmadu Bello University, Zaria, Nigeria and its environment, Veterinary World 7(8): 617-621.

\begin{abstract}
Aim: A 10-year retrospective study was undertaken to determine the prevalence of dog bites reported to the Veterinary Teaching Hospital (VTH), Ahmadu Bello University (ABU), Zaria, and to implement measures to control rabies exposure in the environment.

Materials and Methods: Data on dog bite cases, reported to the VTH of ABU, Zaria, Nigeria between January, 2002 and December, 2011, were retrieved and analyzed using Statistical Package for Social Sciences version 17.0, Chicago, IL, USA.

Result: A total of 236 dog bite-related cases was presented, of which 1.7\% dogs died of rabies. The number of cases (59.7\%) increased through time with the highest number (32) recorded in 2011. Majority of the cases were recorded between June and October of each year. Of the biting dogs, 22.5\% were puppies (1-6 months) and 77.5\% were adults (above 6 months). The human victims were $92.4 \%$, while the dog victims were $7.6 \%$. Eight of the dogs were stray dogs, while 228 (96.6\%) were owned dogs. Of the owned dogs, $71.2 \%$ were free-roaming. Only $22 \%$ of the owned dogs were vaccinated. The most common offending breeds included the Nigerian Indigenous local breeds (73.3\%), cross breeds (24.6\%), Alsatians (0.8\%), Terriers (0.8\%), and Bulldogs (0.4\%).
\end{abstract}

Conclusion: In conclusion, rabies is endemic in Zaria, Nigeria, and the incidence of dog bites is on the rise. Strict measures including vaccination of the dogs and the leash law should be adopted to prevent dog bites.

Keywords: dog bites, prevalence, retrospective study.

\section{I ntroduction}

Rabies, acute viral nonsuppurative encephalitis, is a widely distributed zoonotic disease of major public-health importance [1]. It is one of the most typical zoonosis that has been well-known since more than 4300 years [2]. Domestic dogs are the vectors of rabies [3] in most developing countries, while wildlife rabies is common in developed countries [4]. Both human and animal population are at risk due to the endemicity of rabies in such environments. Thus, rabies, though a preventable zoonosis, is yet to be controlled effectively [5], and its true importance is grossly underestimated [6]. Rabies is mostly caused by the bite of a rabid animal [7]. The Lyssavirus, is present in the saliva of the biting rabid mammal. Virus Inoculated into a wound does not enter the bloodstream, but is taken up at a nerve synapse to travel to the brain, where it causes encephalitis [8]. After multiple rounds of central nervous system replication, the virus spreads centrifugally to the salivary glands and to other innervated sites. Rabies virus

Copyright: The authors. This article is an open access article licensed under the terms of the Creative Commons Attributin License (http: // creative commons.org/licenses/by/2.0) which permits unrestricted use, distribution and reproduction in any medium, provided the work is properly cited. has been transmitted by exposures other than bites that introduce the agent into open wounds, or mucous membranes and organ transplantation [2].

Treatment is not successful once clinical signs have commenced, but the first survivor from clinical rabies without pre- or post-exposure prophylaxis (PEP) for rabies has been documented [8]. Although, canine rabies is under control throughout most of the developed world, it still remains a significant burden in developing countries, particularly in Africa and Asia [9]. Rabies is controlled principally by vaccination of dogs in order to achieve population immunity levels, sufficient to inhibit rabies transmission [10]. Globally, at least 55,000 human deaths are believed to occur every year [11] with $99 \%$ of the deaths occurring in the developing countries of Africa and Asia. In Nigeria, rabies is endemic, and dog has been implicated as the animal that spreads the disease [12]. It is estimated that about 10,000 humans are exposed to rabies each year in Nigeria from dog bites [13].

Because domestic dogs transmit rabies to humans, it is important to understand how the population size, age, sex, movements, accessibility, and habitats affect the spread of rabies in Zaria, so that appropriate control measures can be put in place. 
The aim of this study was to determine the prevalence of dog bite cases using clinical data including age, sex, breeds, season of bites, owned or stray dogs. The data were retrieved and analyzed using case files of all dog bite cases, reported to the Small Animal Unit of the Ahmadu Bello University (ABU) Veterinary Teaching Hospital (VTH), Zaria, Nigeria, between January, 2002 and December, 2011.

\section{Materials and Methods}

\section{Study area}

The ABU is located in the North-western geopolitical zone of Nigeria. The Main Campus of ABU is located in Samaru, a suburb of Zaria in Kaduna State, Nigeria. Samaru is situated on latitude $112^{\circ} 12^{\prime \prime} \mathrm{N}$ and longitude $07^{\circ} 37^{\prime \prime} \mathrm{E}$, at an altitude of 550-700 m. It consists of many residential areas where staff lives, and the VTH is located within the premises of the University. Many cases are usually brought to the hospital daily for various conditions, among which are dog bites.

\section{Statistical analysis}

Data on dog bite cases, reported to the VTH, Zaria, Nigeria between January, 2002 and December, 2011, were retrieved and analyzed using Statistical Package for Social Sciences version 17.0, Chicago, IL, USA.

\section{Results}

A total of 236 cases of dog bite-related incidents was reported to the Small Animal Unit of the VTH, Zaria, Nigeria, of which $1.7 \%$ cases developed rabies during the quarantine (Figure-1).

Table- 1 shows that most of the biting-dogs were above 6-month-old (77.5\%). The majority of the offending-dogs were mostly males (62.3\%), and they were mostly Nigerian Indigenous breeds (73.3\%). Most of the dog bites between January, 2002 and December, 2011 were between June and October (59.7\%).

Table-2 shows that most of the biting-dogs were owned (96.6\%), free-roaming (71.2\%) with only $22 \%$ of them vaccinated.

Table- 3 shows that the human population affected were $(92.4 \%)$ with the legs mostly affected $(76.3 \%)$. The majority of the wounds were bites (87.7\%) which were mostly provoked (55.5\%). Only $13.6 \%$ of the

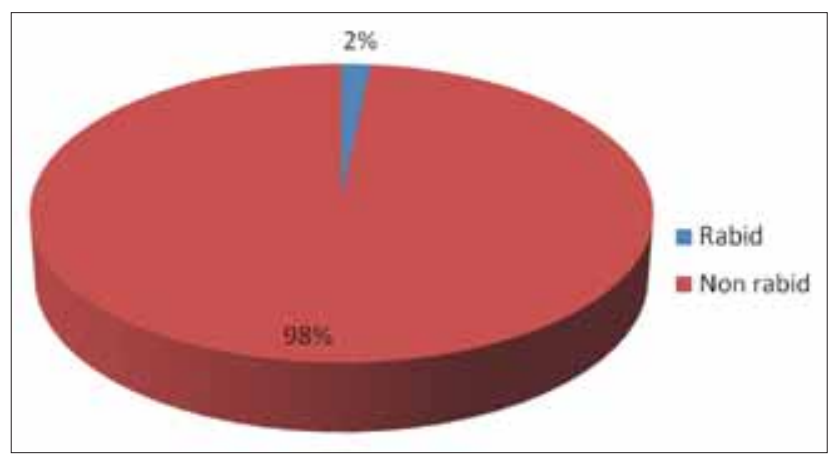

Figure-1: Rabies status of the dog presented to the Veterinary Teaching Hospital Zaria between 2002 and 2011. human victims washed the wound site with soap and water as a first aid treatment in dog bites.

\section{Year and month distribution of dog bites}

The number of cases increased through time with the highest number of dog-bite cases, 32 recorded in 2011 (Figure-2).

\section{Discussion}

The findings of the present study confirm the results obtained by Awoyomi et al. [14] that domestic dogs are the principal reservoirs and vectors of rabies in Nigeria, and that they play a major role in the transmission rabies to humans through bites. This study revealed that older dogs (77.5\%) were more likely to bite than younger dogs (22.5\%). This could possibly be due to the fact that older animals have a tendency to be over-protective and develop a tendency to bite. Majority of the offending dogs were male (62.3\%) which showed that male dogs are more aggressive than

Table-1: History of offending dogs and seasonal distribution.

\begin{tabular}{lcc}
\hline Clinical data & $\begin{array}{c}\text { Number } \\
\text { of dogs }\end{array}$ & Percentage \\
\hline Age groups of offending & & \\
dogs (months) & & \\
$<6$ & 53 & 22.5 \\
$>6$ & 183 & 77.5 \\
Total & 236 & 100 \\
Sex of offending dogs & & \\
Male & 147 & 62.3 \\
Female & 89 & 37.7 \\
Total & 236 & 100 \\
Breeds of the offending dogs & & \\
Nigerian indigenous breed & 173 & 73.3 \\
Cross-breed & 58 & 24.6 \\
Alsatian & 2 & 0.8 \\
Terrier & 2 & 0.8 \\
Bulldog & 1 & 0.4 \\
Total & 236 & 100 \\
Seasons of bites & & \\
June to October & 141 & 59.7 \\
November to April & 95 & 40.3 \\
Total & 236 & 100 \\
\hline
\end{tabular}

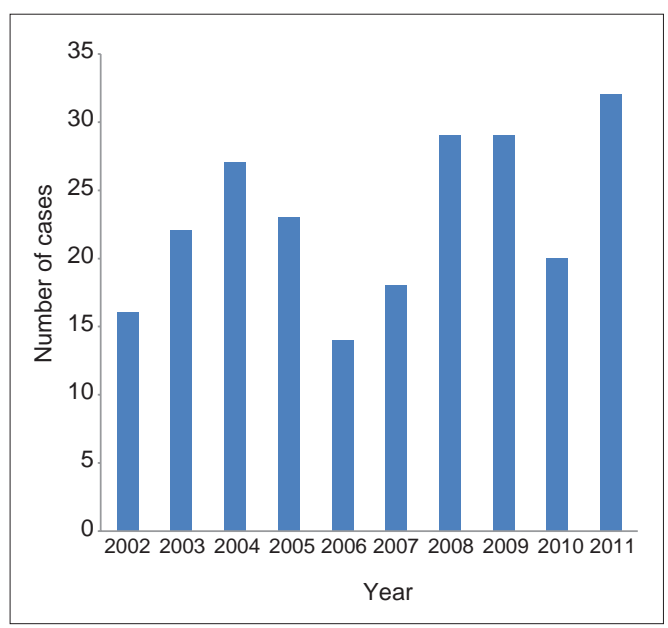

Figure-2: Annual incidence of dog bites presented to the VTH, Zaria between J anuary 2002 and December 2011. 
Table-2: Management practices of dogs brought to $A B U$, VTH, Zaria in bite cases between January, 2002 and December, 2011.

\begin{tabular}{lcc}
\hline Management practice & $\begin{array}{c}\text { Number } \\
\text { of dogs }\end{array}$ & $\begin{array}{c}\text { Prevalence } \\
(\mathbf{\%})\end{array}$ \\
\hline Dog ownership & 8 & 3.4 \\
$\quad$ Stray dogs & 228 & 96.6 \\
Owned dogs & 236 & 100 \\
$\quad$ Total & & \\
Management of owned dogs & 162 & 71.2 \\
$\quad$ Free-roaming & 66 & 28.8 \\
Leased & 228 & 100 \\
$\quad$ Total & & \\
Vaccination status & 52 & 22 \\
Vaccinated & 184 & 78 \\
Unvaccinated & 236 & 100 \\
Total &
\end{tabular}

$\mathrm{ABU}=\mathrm{Ahmadu}$ Bello University, $\mathrm{VTH}=$ Veterinary Teaching Hospital

Table-3: History of the wound and treatment.

\begin{tabular}{|c|c|c|}
\hline Wound & $\begin{array}{l}\text { Number } \\
\text { of dogs }\end{array}$ & $\begin{array}{c}\text { Prevalence } \\
(\%)\end{array}$ \\
\hline \multicolumn{3}{|l|}{ Victims of dog-bites } \\
\hline Humans & 218 & 92.4 \\
\hline Dogs & 18 & 7.6 \\
\hline Total & 236 & 100 \\
\hline \multicolumn{3}{|l|}{ Nature of wounds } \\
\hline Bites & 207 & 87.7 \\
\hline Scratch & 29 & 12.3 \\
\hline Total & 236 & 100 \\
\hline \multicolumn{3}{|l|}{ Bite sites in humans } \\
\hline Legs & 180 & 76.3 \\
\hline Gluteal region & 19 & 8.1 \\
\hline Upper arm & 18 & 7.6 \\
\hline Finger & 4 & 1.7 \\
\hline \multicolumn{3}{|l|}{ Bite site in dogs } \\
\hline Neck & 15 & 6.3 \\
\hline Total & 236 & 100 \\
\hline \multicolumn{3}{|l|}{ Circumstance of bite } \\
\hline Provoked & 131 & 55.5 \\
\hline Unprovoked & 105 & 44.5 \\
\hline Total & 236 & 100 \\
\hline \multicolumn{3}{|l|}{ First aid treatment in humans } \\
\hline Washing with soap and water & 32 & 13.6 \\
\hline No treatment & 204 & 86.4 \\
\hline Total & 236 & 100 \\
\hline
\end{tabular}

female dogs. This confirms the previous study by Kilic and Sarierler [15]. In addition, Gershman [16] found that male and unneutered dogs are more likely to be aggressive compared with female and neutered dogs, and agrees with the results obtained in the present study.

There is considerable debate on whether or not certain breeds of dogs are inherently more vicious. The observation in this study showed that the Nigerian indigenous breeds are more likely to attack than other foreign breeds. This may be because less attention is usually given to Nigerian Indigenous dogs, these dogs end up roaming around in search of food. Based on the fact that they are the breed with the highest population there is a tendency for them to have become very aggressive due to neglect, thus exposing humans and dogs to their attacks. However, every breed poses a threat to its victim.

Prevalence of dog bites was recorded predominantly in the raining season, June and October (59.7\%) which corresponds to the breeding season of dogs in Nigeria. This may be explained by the fact that on warm, summer days (correspondingly, the hot-humid, rainy season), people and dogs spend more time together, and children are less supervised by parents, thus increasing the risk for such incidents [17]. Similarly, the period coincides with the holiday period, when children, as well as dogs, are more active and tend to play outside, increasing the possibility of encountering one another. Running past dogs or startling the dog which are often common during the season can trigger a possible attack [17].

The increased number of humans (92.4\%) bitten by, or exposed to, rabies-suspected dogs observed in this study reflect the increased threat of rabies transmission. It should be emphasized that obviously, the prevalence of dog bite as recorded in the VTH, Zaria, is less than the actual number of dog-bite cases. This is because many people would normally not report to the hospital unless they suspect, or they are certain about abnormality in the behavior of the dogs. Many people may also be ignorant of the importance of reporting to the VTH as a requirement. Furthermore, the number of dog bites may rise with an increase in dog population, and the increased usage of dogs as companions and guard animals [18]. Consequently, a substantial increase in rabies transmissions and associated deaths may occur, in rural areas where dogs are unvaccinated, unleashed and have free movement, thereby increasing the risk of exposure of man to rabies [18]. In human victims, bite wounds were mostly inflicted on the legs $(76.3 \%)$, and the finger was the least affected (1.7\%).

Majority of the offending dogs were owned dogs (96.6\%), with only few stray dogs (3.4\%). This agrees with the findings of previous authors [19-22], and this may be explained by the fact that owned dogs are closer to home and tend to protect their territory. Some of the owned dogs are free-roaming (71.2\%), which may be more aggressive than stray dogs especially when they are in their territory. Most of the owned dogs (96.6\%) were unvaccinated (78\%) which may be due to lack of awareness or poverty [23,24]. This agrees the findings by Ezeokoli and Umoh, [19]. Majority of the wounds were bites (87.7\%) which were provoked (55.5\%). This study confirmed previous work by Rosado et al. [25] that most of the circumstances of bites were provoked. Circumstances leading to provocation may include interfering between a dog and its food, encroaching on its territory, intervention when dogs fight, sickness or injury, or an older dog may become over-reactive. 
Due to the endemicity of rabies in Nigeria, including Kaduna State, Nigeria [26]; all victims who came to the VTH, Zaria, with bites from rabies-suspected animals were considered for PEP at day $0,3,7,14$, and 28 . It is very necessary that the first aid be administered immediately after dog bite to reduce the viral load at the site of the bite. This was done by washing with plenty of water, soap, and alcohol. The observation that a large percentage of victims (86.4\%) did not carryout first aid by washing dog bite wound with soap and water suggests increased danger of infection.

We found an increasing trend in the number of reported cases in recent years with the highest incidence of cases reported in 2011 (32) which may be due to heightened awareness about the consequences of rabies; an increase in the availability of PEP; and easy access to medical facilities for dogs. Furthermore, other factors increase in the people's trust in services and their tendency to report rose, as well as increase dog population and movement. An increased rabies incidence in Africa and Asia has been largely attributed to population growth of dogs [26].

\section{Conclusions}

In conclusion, this study revealed the increased number of humans bitten by, or exposed to, rabies-suspected dogs and the endemicity of rabies in Zaria. Dog bites occur more during the raining season. Male dogs are more prone to bite than females and fewer dogs are vaccinated with regards to the population of the dogs.

\section{Recommendation}

The results of the present study suggest a need to educate the public about the magnitude of dog-bite problems, enforce the leash law and impound stray dogs as an integral part of preventive measures. There should be public enlightenment workshops, aimed at educating the public of the need to report all cases of dog bite to the VTH, Zaria. Finally, more awareness should be created on the public health importance of rabies, and to ensure that all dog owners vaccinate their dogs regularly.

\section{Authors' Contributions}

A.M Ehimiyein conceived, designed, and supervised the study; F Nanfa carried out the study; I.O Ehimiyein edited and type-set the work; B. M Jahun provided the necessary records needed. All authors read and approved the final manuscript.

\section{Acknowledgements}

The authors are grateful to Professor J.O. Ayo of the Department of Veterinary Physiology, ABU, Zaria, for proof reading this manuscript and also the management of the Ahmadu Bello University Veterinary Teaching Hospital for providing the records used in this study. Funding of this study was done by the authors.

\section{Competing I nterests}

The authors declare that there are no competing interests.

\section{References}

1. Ly, S., Buchy, P., Heng, N.Y., Ong, S., Chhor, N., Bourhy, H. and Vong, S. (2009) Rabies situation in Cambodia. PLoS Negl. Trop. Dis., 3(9): e511.

2. Takayama, N. (2008) Rabies: A preventable but incurable disease. J. Infect. Chemother., 14(1): 8-14.

3. Burgos-Caceres, S. (2011) Canine rabies: A looming threat to public health. Animals, 1: 326-342.

4. Jackson, A.C. (2011) Updates of rabies. Res. Rep. Trop. Med., 2011(2): 31-43.

5. Coleman, P.G., Fevre, E.M. and Cleaveland, S. (2004) Estimating the public health impact of rabies. Emerg. Infect. Dis., 10(1): 140-142.

6. Kitala, P.M., McDermott, J.J., Kyule, M.N. and Gathuma, J.M. (1999) Community-based active surveillance for rabies in Machokos District, Kenya. Prev. Vet. Med., 44(2000): 23-85.

7. Yousaf, Z.M., Qasim, M., Zia, S., Khan, M.R., Ashfaq, U.A. and Khan, S. (2012) Rabies molecular virology, diagnosis, prevention and treatment. Virol. J., 9: 50.

8. Willoughby, Jr., R.E., Tieves, K.S., Hoffman, G.M., Ghanayem, N.S., Amlie-Lefond, C.M., Schwabe, M.J., Chusid, M.J. and Rupprecht, C.E. (2007) Survival after treatment of rabies with induction of coma. New. Engl. J. Med., 352(24): 2508-14.

9. Blanton, J.D. and Rupprecht, C.E. (2008) Travel vaccination for rabies. Expert Rev. Vaccines, 7(5): 613-620.

10. Fitzpatrick, M.C., Hampson, K., Cleaveland, S., Meyers, L.A., Townsend, J.P. and Galvani, A.P. (2012) Potential for rabies control through dog vaccination in wildlife-abundant communities of Tanzania. PLoS Negl. Trop. Dis., 6(8): e1796.

11. WHO. (2005) WHO expert consultation on rabies. World Health Organ. Tech. Rep. Ser., 931: 1-88.

12. Qasim, A.M., Obadua, A.A., Okewole, P.A., Tekki, I.S. and Omoleye, O.S. (2013) Rabies in a vaccinated 9-month-old German Sheperd Dog, Akure, 2010: A case report. Case Rep Vet Med, 2013: 3.

13. Nawathe, D.R. (1980) Rabies control in Nigeria. Bull. Off. Int. Epizoot, 92: 129-139.

14. Awoyomi, O., Adeyemi, I.G. and Awoyomi, F.S. (2007) Socioeconomic factors associated with Non-vaccination of dogs against rabies in Ibadan, Nigeria. Niger Vet. J., 28(3): 59-63.

15. Kiliç, N. and Sarierler, M. (2003) Dog bite wounds: A retrospective study (1102 cases). Yyü. Vet. Fak. Derg., 102(2): 86-88.

16. Gershman, K.A., Sacks J.J. and Wright, J.C. (1994) Which dog bites? A case-control study of risk factors. Pediatrics, 93: 913-917.

17. Mazigo, H.D., Okumu, F.O., Kweka, E.J. and Mnyone, L.L. (2010) Retrospective analysis of suspected rabies cases reported at Bugando Referral Hospital, Mwanza, Tanzania. J. Glob. Infect. Dis., 2(3): 216-220.

18. Tang, X., Luo, M., Zhang, S., Fooks, A.R., Hu, R. and Tu, C. (2005) Pivotal role of dogs in rabies transmission. Emerg. Infect. Dis., 11(12): 1970-2.

19. Ezeokoli, C.D. and Umoh, J.U. (1987) Epidemiology of rabies in northern Nigeria. Trans. R. Soc. Trop. Med. Hyg., 81(2): 268-272.

20. Overall, K.L. and Love, M. (2001) Dog bites to humans - Demography epidemiology, injury and risk. J. Am. Vet. Med. Assoc., 218(12): 1923-1934.

21. Mendez, G.R., Gomez, T.M., Somoza, A.I., Liras, M.J., Pais, P.E. and Vela, N.D. (2002) Dog bite related injuries treated in a pediatric surgery department: Analysis of 
654 cases in 10 years. An. Esp. Pediatr., 56: 425-429.

22. Bata, S.I., Dzikwi, A.A. and Ayika, D.G. (2011) Retrospective study of dog bite cases reported to ECW aveterinary clinic, Bukuru, Plateau state, Nigeria. Sci. World J., 6: 17-19.

23. Adedeji, A.O., Okonko, O.I., Eyarefe, O.D., Adedeji, O.B., Babalola, E.T.,Ojezele, M.O., Nwanze, J.C. and Amusan, T.A. (2010) An overview of rabies - History, epidemiology, control and possible elimination. Afr. J. Microbiol. Res., 4(22): 2327-2338.

24. Rosado, B., Garcia-Belenguer, S., Leon, M. and Palacio, J.
(2008) A comprehensive study of dog bites in Spain, 19952004. Vet. J., 179(2009): 383-391.

25. Ehimiyein, A.M., Niezgoda, M., Orciari, L., Kuzmin, I., Osinubi, M.O.V., Ehimiyein, I.O, Adawa, D.A.Y., Abdullahi, S.U., Ogunkoya, A.B. and Rupprecht, C.E. (2010) Rabies cases in dog markets in Kaduna State, Northern Nigeria. Int. J. Infect. Dis., 14: e476.

26. Hampson, K., Dushoff, J., Bingham, J., Bruckner, G., Ali, Y.H. and Dobson, A. (2007) Synchronous cycles of domestic dogs rabies in Sub-Saharan Africa and the impact of control efforts. Proc. Natl. Acad. Sci., 104(18): 7717-7722.

$* * * * * * * *$ 